Article

\title{
Two Heads Are Better Than One-Entrepreneurial Continuous Learning through Massive Open Online Courses
}

\author{
Agnieszka Żur ${ }^{\circledR}$ \\ Department Of Entrepreneurship and Innovation, Institute of Economics, College of Economics, Finance And \\ Law, Cracow University of Economics, 31-510 Kraków, Poland; zura@uek.krakow.pl
}

Received: 28 January 2020; Accepted: 1 March 2020; Published: 7 March 2020

check for updates

\begin{abstract}
Globalisation and digital technology have changed the means and mechanisms of knowledge acquisition. The rapidly expanding open-access online resources and various digital learning platforms present new opportunities in the area of continuous entrepreneurial learning, including that of corporate employees. This paper draws on knowledge spillover theory in order to explore the potential of Massive Open Online Courses (MOOCs) as enablers of knowledge exchange, consolidation and new knowledge creation through connecting geographically and institutionally distant actors. The research design is based on a qualitative interpretative approach exploiting a triangulation of methods by using sets of quantitative data collected from MOOC participants, five focus group interviews and text content of online course discussion groups. This study contributes to our understanding of how digital technologies enable entrepreneurial learning on a massive scale. It identifies three factors which can trigger intense horizontal knowledge spillovers on a massive scale: (i) participants' common interests and aspirations, (ii) induced mobilisation, and (iii) participants' optional anonymity. Additionally, the findings of this study provide useful information for potential MOOC creators regarding the design and delivery of MOOCs targeting a high density of participant interactions.
\end{abstract}

Keywords: entrepreneurial education; continuous learning; digital learning; online learning; MOOCs

\section{Introduction}

Entrepreneurship today is conceptualised as a universal set of skills and attitudes that can be applied in every context, and that is essential at all stages of a professional career [1,2]. Employee-level entrepreneurial competence is often indicated by research and practice as the prime type of competence, necessary in today's business reality to handle proactively contemporary workplace challenges [3-6]. This is why employees often seek to develop their entrepreneurial skills throughout their career by pursuing continuous lifelong learning. Taking the rapid evolution of information and communication technologies into account, alongside the fast-paced changes in business and an unprecedented influx of innovation, it seems critical for employees to capture up-to-date entrepreneurship knowledge in feasible and cost-effective ways. Yet, the research related to continuous entrepreneurial learning is very limited. To date, the majority of entrepreneurial courses have been developed by business schools as part of secondary and vocational education programmes [7]. In a systematic review of entrepreneurship education research, Nabi et al. point out that the majority of papers has remained focused on higher education programmes, especially those relating to the creation of new businesses [8]. Additionally, the authors have signalled that the digital technology perspective of continuous education is under-researched and that there is a wide gap in our understanding of employee learning in the digital age [9]. Considering the rapid growth and diffusion of digital technologies, it seems important that we examine the potential value of various emerging digital formats relative to continuous entrepreneurial education. 
This study seeks to explore the potential of Massive Open Online Courses (MOOCs) in continuous post-graduate entrepreneurial education, and specifically that of employees of large organisations. The research design is based on a qualitative interpretative approach exploiting a triangulation of methods by using quantitative data sets collected among participants of a MOOC dedicated to upgrading employee entrepreneurial skills, the content of online discussion groups, as well as focus group interviews with selected participants to strengthen exploratory research by validation. The focus of this study is on the digital enablers of knowledge spillovers within a MOOC, which brought together 2905 participants from 98 countries. MOOCs present a valuable research ground for entrepreneurial education given that they connect massive numbers of learners simultaneously and, therefore, hold the potential of creating an environment, which is rich in knowledge. According to the knowledge spillover theory of entrepreneurship (KSTE), a context that is rich in knowledge generates entrepreneurial opportunities [10].

This study makes several contributions. Given the rapid growth and expanding possibilities of digital technology, it seems important that we examine the potential value of various digital means relative to entrepreneurial education. Understanding how knowledge is diffused within a time-restricted purposely designed digital environment will advance our notion of continuous entrepreneurial education in the digital age. The presented case study adds to the already existing evidence on the mechanisms and practices related to cross-sector knowledge transmissions, knowledge spillover effects and digital community learning by highlighting the opportunities and advantages that MOOCs present in this regard. Recently, research has indicated that digital platforms play an increasingly important role in entrepreneurial education [11-13]. As Helfat and Raubitschek [12] point out, digital platforms do not automatically generate positive knowledge exchange effects without purposeful action by platform leaders (p. 1392). In regard to MOOCs, their creators and facilitators are responsible for orchestrating the dynamics of knowledge exchange for all MOOC participants. Hence, this study offers important insights and practical implications for institutions willing to create and develop digital learning experiences, by identifying the conditioning factors of knowledge spillover effects.

The paper starts with an introduction to the main concepts: entrepreneurial learning, knowledge spillover theory and Massive Open Online Courses. It then describes the goals, design and development process of the showcased MOOC. Next, it presents the outcomes of the implemented MOOC. The outcomes, theoretical contributions and practical implications for entrepreneurial learning are discussed. The paper concludes with some final remarks and suggestions for future research.

\section{Theoretical Background}

\subsection{Continuous Entrepreneurial Education in the Digital Age}

The rapidly changing demands of a knowledge-based economy create the necessity for lifelong learning and urgency for upskilling entrepreneurial competence among individuals. The European Commission defines entrepreneurship as one of the eight key competences for lifelong learning [14]. In these official recommendations, educators are encouraged to adopt innovative pedagogies for entrepreneurial courses in order to achieve positive impact. EU documentation conceptualises entrepreneurship broadly as the ability to turn ideas into action, which involves creativity, innovation and risk-taking, as well as the ability to plan and manage projects in order to achieve objectives [14].

Contemporary education for entrepreneurship is driven by the goal to develop real-life entrepreneurial skills and behaviours. Some scholars go so far as to claim that the goal is to change thinking and behavioural patterns [15]. Rae [15] defines entrepreneurial learning as "led by creativity, informality, curiosity, emotion and its application to personal and real-world problems and opportunities" (p. 595). Hence, contemporary education for entrepreneurship includes the promotion of personal skills and training related to entrepreneurship, such as creativity, problem-solving, communication and networking skills. Authors have repeatedly emphasised that fostering 
entrepreneurship as a mindset and the cultivation of entrepreneurial skills involves the transition of entrepreneurship pedagogy from traditional content-centred approaches to socio-constructivist learning-centred instruction [7,16-18]. In socio-constructivist learning, students construct knowledge and derive meaning from their own experiences, as well as the experience and reflection of others. New knowledge is perceived as the synergetic effect of exchange and community learning. In the previous decade, digital technologies transformed how individuals develop their entrepreneurial skills providing new tools and functionalities that can add substantial value to traditional learning and training modes, radically transforming educational processes towards more socio-constructivist approaches, which emphasise the role of social interactions in knowledge construction processes [7,18]. Scholars indicate that digital platforms have already transformed individual learning in this regard to a large extent $[19,20]$ by producing learning materials in the form of open-source content, online consulting and support centres, open source e-learning courses and training programs [21]. The use of online learning is on the rise; many professionals use online learning formats for their own upskilling, taking advantage of an enhanced, personalised and collaborative learning environment [22]. Chen defined online learning, or eLearning, as the combination of technology with learning, delivered using telecommunications and information technology [23]. In addition to low costs, other advantages such as convenience, standardised delivery, self-paced learning, and the variety of available content, have made online learning an attractive opportunity for many [24].

Today, digitalisation and digital platforms, which rely on voluntary social interactions, offer new opportunities for employee online learning practices and can become the basis of global networks reaching vastly dispersed actors. Autio et al. have outlined three important advantages of digital learning formats [11]. First, digitalisation decouples form and function, reducing the importance of assets and physical infrastructure and thus the cost of communication. Second, it promotes disintermediation enabling direct seamless connections between various actors without any intermediary bodies. Finally, it drives generativity, enabling dispersed, often very distant and diverse audiences to create and take advantage of digital platforms. These three properties radically broaden access to learning resources and lift the limitations of traditional learning formats, enabling massive numbers of actors to learn together and share across new digital networks.

The network approach in entrepreneurship theory rests on the assumption that the networks in which entrepreneurs are embedded determine the information, knowledge and resources they can access $[25,26]$. Networks are critical for learning in socio-constructivist approaches, especially in the context of entrepreneurship. The Opportunity Based View of entrepreneurship defines opportunity development as a creative process in which the entrepreneur develops new ideas by recombining dispersed bits of incomplete knowledge that is spread across people, places and times, in novel ways that serve to create new value. This stream of research suggests that, due to the limited availability of opportunities, the process of opportunity discovery is conditioned by the number of knowledge pools with which the entrepreneur is directly connected $[27,28]$. Access to knowledge pools, interaction and exchange appear to be at the heart of entrepreneurial learning effectiveness and have been largely developed in the past decade within the remits of the knowledge spillover theory of entrepreneurship. This theory implies that 'the asymmetries in knowledge across individuals also create asymmetries in opportunities across individuals [10] (p. 760). This provides an explanation as to why some individuals are more entrepreneurial than others and presents knowledge spillovers as the key explanatory variable. As knowledge is partially tacit and localised, its transfer requires interactions that have been traditionally limited by location [29]. Information technology increases proximity by providing a digital connection between parties. Therefore, location is no longer a parameter that individuals and firms need to take into consideration in order to increase their exposure to potential knowledge spillovers. Therefore, through digital platforms, knowledge spillovers can be orchestrated on a wide scale resulting in potentially higher exposure to opportunity pools. This is especially significant for the continuous education of professionals, because they can easily overcome firm or industry homogeneity by gaining access to diverse knowledge pools that would help them expand their professional capacity. 
Both network theory and knowledge spillover theory suggest that effective entrepreneurial education requires access to larger communities, networks and knowledge pools, where knowledge can be exchanged and developed. These criteria are met by many new digital learning formats.

\subsection{Massive Open Online Courses}

In recent decades, globalisation combined with technological advancements has changed the context of knowledge spillovers, as well as the sources and mechanisms of knowledge production and absorption. Information technology enables individuals, institutions and organisations to connect in ways that were unavailable in the past [30]. As such, it presents numerous opportunities for entrepreneurial continuous learning.

Massive Open Online courses (MOOCs) are an online learning format developed in the past couple of decades, which can be defined as online courses designed for a massive number of participants that can be accessed by anyone, anywhere, with an internet connection, has no entry qualifications and offers a complete course experience online for free [31]. Large MOOC platforms such as EdX, Coursera or Udacity are the main global providers, while numerous smaller platforms also exist. MOOCs are growing in number and constantly foster new trends, such as switching from a traditional university target group to business learners. MOOCs fundamentally enrich web-based teaching and e-learning [16,32].

MOOCs exist in two basic formats. xMOOCs are more linear, instructor-guided courses modelled on traditional course materials, theories and teaching methods, most often accessible as self-paced models with no time restrictions. Connectivist MOOCs (cMOOCs) enable participant interaction and knowledge exchange, are delivered within a set time period and are, most often, moderated in real time. This type of MOOC is based on connectivist theories [33] and puts an emphasis on connecting learners rather than presenting content. The focus is on networks and learner participation in the construction of content [6,34]. These courses rely on digital multi-sided platforms to bring together individuals from around the world and from many professional contexts. Digital multi-sided platform-based formats provide interfaces between two or more groups of actors on different "sides" of the platform, including providers of complementary assets [12]. These platforms mediate interactions between groups of actors composed of: the platform leaders, actors on different sides of the platform, complementary asset providers (such as software) and input suppliers to the platform leader. Digital multi-sided platforms rely on the cross-side exchange of content across the platform, in which the value to a party on one side of the platform depends on the number and quality of the parties on the other side(s) of the platform [12]. Hence, MOOCs based on digital multi-sided platforms facilitate knowledge exchange in a virtual community; they enable just-in-time learning by connecting geographically and institutionally distant actors on a massive scale [32,35]. This presents a huge benefit for working individuals, who choose to expand their knowledge and grow their skills in their own time, since learning in a diverse community through traditional face-to-face sessions is most often impossible to achieve. Additionally, traditional one-on-one learning formats are time specific, while MOOCs offer flexibility; participants can access online content anytime, anywhere, continue a conversation with other learners online and take part in online sessions that are suitable for them.

While existing studies explain the core success factors of MOOCs, as well as the different formats, expansion strategies and knowledge facilitation mechanisms [36-39], significantly less attention has been devoted so far to the study of the adoption of MOOCs in continuous entrepreneurship education.

\section{Research Design}

The aim of this research is to explore the potential role of MOOCs as effective means of continuous entrepreneurial education. The research design is grounded on the exploratory case study approach. Among the five potential justifications for single case study research, [2] identifies unusual cases as a legitimate reason for capturing rare, yet relevant evidence. The exploration of MOOCs as a means of 
continuous entrepreneurial education for employees falls into this category, as it represents an unusual case, with little relevant research conducted so far.

The case study presents the design, development and implementation of a MOOC dedicated to employee-level entrepreneurship skills (intrapreneurship). The choice of topic was based on research on already existing MOOCs dedicated to particular entrepreneurship themes. Initial research exposed that online resources in the area of intrapreneurship are scarce and fragmented. Intrapreneurship remains more of a practice than a theory [40]. According to Class Central (https://www.classcentral.com/), the largest MOOC directory, although there are many MOOCs on entrepreneurship (including those upgrading entrepreneurial competences), thus far no MOOC is dedicated specifically to intrapreneurship. This presents a gap in the current MOOC portfolio. The intension was to verify the deliverables of the course against participants' expectations and to test the potential role of MOOCs in connecting dispersed actors of entrepreneurship processes in an area, which is underserviced by current online digital resources.

In terms of exploratory research, it is important to use multiple sources of data in order to deliver robust qualitative and quantitative evidence for theory development [41]. Using a mixed methods approach, the authors have gathered sets of data following three principles of data collection: (i) use multiple sources of evidence, (ii) create a case study database, and (iii) validate data and maintain a chain of evidence [42]. Data collection commenced with a pre-course survey filled in by participants upon registration to the course (often several weeks prior to the course). This was a simple short form through which the developers collected data regarding the participants' profile, more specifically: age, education, country of origin, professional experience, employment status, area of employment and position. The purpose was to establish whether the course connects people across sectors, age groups and professions, creating a heterogeneous community of learners.

Throughout the duration of the course, the data collection continued by keeping track of all important indexes, such as participation rate, number of forum posts, forum threads, further enrolments, drop-outs, items visited, points achieved and e-tivities (online interactive activities) completed. All forum activities and online discussion groups were tracked, and the contributions to course activities were evaluated separately.

Upon completion of the course, the developers collected data via a post-course survey. The aim of this data collection process was to gain insight into the respondents' subjective individual course evaluation with particular emphasis on peer interaction and quality of knowledge exchange. The post-course survey was very concise, since longer surveys have very low return rates in MOOCs [43]. Five dimensions of user experience were measured: (i) whether user expectations were met, (ii) whether users benefitted from the experience, (iii) whether they found the knowledge exchange valuable overall, (iv) how was the course beneficial for their professional life and (v) whether they would recommend the course to others. Questions were formulated as follows: "How would you rate the course in regard to." All items were measured using a 5-point Likert scale ranging from very poor to excellent.

The last phase of data collection were focus group interviews. The objective of this step was to collect additional evidence that would supplement the data collected via the post-course survey. Hence, after completion of the moderated version of the course, 21 purposely selected participants were interviewed in five focus groups. Heterogeneity of the group was ensured by selecting participants from diverse professional backgrounds. Age and years of professional experience served as additional diversification criteria. Heterogeneity, however, was limited by geographical proximity; the focus groups were carried out in the home countries of the MOOC developers: Austria, Germany and Poland. The selection of focus group respondents resulted in a combination of different participant profiles: professionals from IT, HR, marketing, engineering and education. Most were managers, with two entrepreneurs, two small business owners, and two students (working graduates) to ensure a diverse sample of respondents furnishing diverse perspectives on the course outcomes. The focus groups were carried out during the first month following course termination by individual developers (on two occasions, two developers were present at the same interview). The focus group interviews consisted 
of the same questions as the post-course survey, but were developed with "why" and "how" type follow-up questions and questions asking for specific examples of most valued experiences. The focus group method provides valuable quality controls to data collection, as respondents provide checks and balances on each other, weeding out false or extreme views, so that a shared consistent view can be quickly assessed [40]. The group discussions that emerged during the focus group interviews were valuable, as they corresponded to the way in which opinions are produced, expressed and exchanged in everyday life [40]. As such, the focus group interviews helped to validate the results of course forum analyses and the post-course surveys.

Data analysis was carried out for each data set. The quantitative data from different stages (pre, post and during the course) were evaluated on a descriptive basis. Additionally, all e-tivities, which took place during the course, were analysed and summarised by the developers. First, a quantitative analysis was carried out counting all measureable data, such as number of contributions, number of contributors and number of examples/inputs shared. Next, the e-tivities were subject to content analysis using the MAXQDA software. The content analysis process enabled the identification of particular knowledge hubs and knowledge streams "spilled" by the participants. The post-course focus group data was transcribed and coded according to pre-defined categories congruent with post-course survey items. During the coding process, however, the focus was on the most valued aspects of knowledge sharing.

\section{Case Study}

\subsection{MOOC Development Process}

The MOOC was designed in partnership between two university and two industry partners. The intension was to create a moderated MOOC, which would be a combination of an XMOOC with meaningful state-of-the-art inputs on intrapreneurship and a designed learning pathway, and of a cMOOC, which would provide plenty of opportunities for exchange of knowledge, experience, best practices, successes and failures concerning employee-level entrepreneurship. The developers' intention was to bring together people who exercise or wish to exercise this practice and to build the foundations for solid cross-side exchange among course participants.

The development process started one year in advance, when all partners met to determine the course methodology. The first step was the definition of the target group. As intrapreneurship implies the identification and exploitation of business opportunities within established companies, the developers decided to address the course to multiple business actors: managers of all levels, employees and trainees. The primary target group, however, was identified as young employees, and low-level and middle managers who are the most crucial actors of intrapreneurship. Prior to the course, 21 experts were interviewed according to an interview guide with 6 open questions, in order to establish the recognition of MOOCs among target groups, gain insight into their needs and expectations, as well as any potential barriers to participating in the MOOC. The interviewees were 11 business experts (HR, business development or innovation professionals) and 10 academics (entrepreneurship domain), some with significant online training experience. The results of these interviews are beyond the scope of this particular study; they simply enabled the developers to fine-tune the design and content to the needs of the target group.

The learning outcomes were defined so that learners who completed the course would not only gain new knowledge, but also practical skills. The course introduced tools relevant for intrapreneurship, which the participants could put to use while working in their online teams as part of the course. Upon defining the course objectives and envisaging the learning outcomes, the partners began the learning design process through regular online working sessions and two video recording sessions.

The success of the course was heavily reliant on peer interactions. Hence, participants' interactions resulting in knowledge sharing and integration were at the core of the design process, which resulted in several important developments. First, regarding strategies for increasing participation in the discussion 
forums, instructors used course announcements to encourage learner participation. Additionally, standard items of the MOOC (videos, readings, quizzes, tests) encouraged learners to engage in discussion by adding dedicated messages to instructions, for example: "We hope that you will take the time to not only watch the lecture but also participate in the forum by asking and answering questions of others and sharing your thoughts." Second, besides standard items of a MOOC, seven e-tivities were planned to stimulate active user participation following the e-moderation concept by Gilly Salmon [44]. E-tivities (eLearning interactive activities) are multi-step didactical frameworks to enable learners to become co-creators of an online course, as it is not possible to capture value within a multi-sided digital platform-based ecosystem without massive contribution by the participants [13]. An example on an e-tivity is provided below (Figure 1).

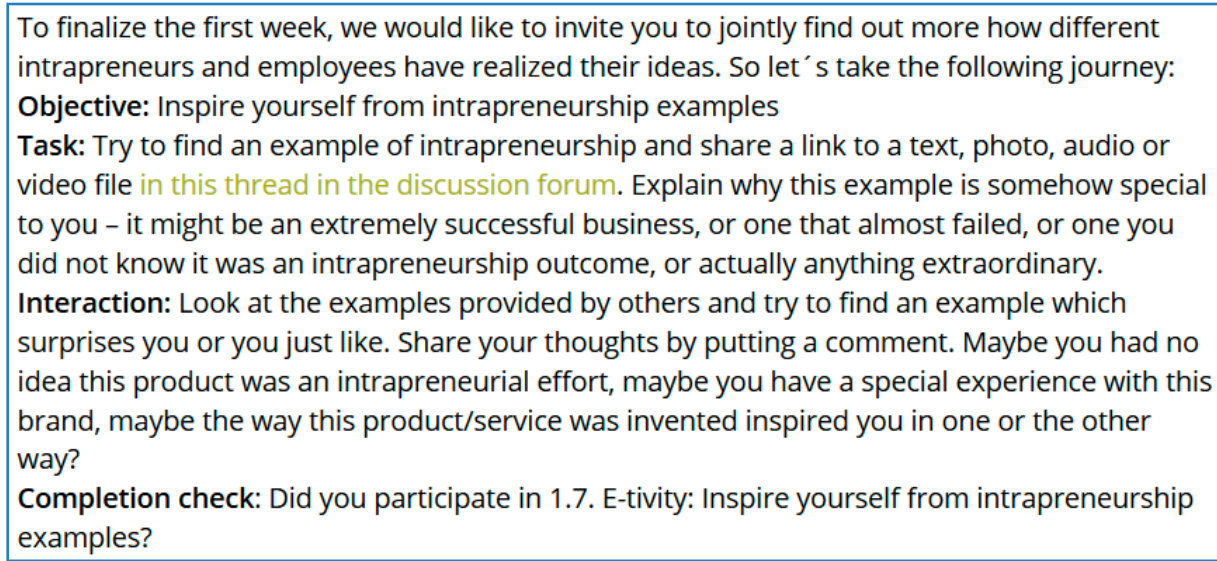

Figure 1. e-tivity 2 of the Intrapreneurship MOOC: Inspire Yourself From Intrapreneurship Examples.

Third, active moderation was planned throughout the course to initiate and enable an extensive and multi-stream participant exchange in the discussion forum. A critical element of the design process was to provide access to various knowledge pools and plenty of opportunities for participants to present their own knowledge, experience and reflections, as well as their original entrepreneurial ideas, and receive peer feedback. The MOOC was meant to become a platform stimulating knowledge sharing between participants and generating robust cross-side exchange. Additionally, the developers intended to encourage participants to engage in online teamwork in international teams of up to seven people (with controlled team configurations). The aim was to develop a pitch, and brought participants from different backgrounds together and enabled closer and more informal interactions.

The course was delivered in weekly modules with approximately five hours study time per week. It offered different course tracks with four certification options. Keeping in mind that the course targets business people, presumably working full-time, flexibility and participation options were a clear necessity. Depending on the course track, the duration of the MOOC was between four and six weeks in total.

Promotion began five months prior to the course launch and was intensified in the last month, mainly through online channels and targeting a business audience. Alongside the activation of business networks of the four course-developing institutions, businesses (CEO, HR managers, innovation managers, consultants etc.) were contacted directly to promote the course to their peers. The participants signed up for the course on the platform themselves.

The course was open and free for everyone and was conducted entirely online. After implementing the moderated version, the course remained available in a self-paced mode without the certification and teamwork options. 


\subsection{Outcomes}

The completion rate of this course was far above MOOC average completion rates, which are usually below 13\% [43]. In total, 2951 people enrolled for the course and $70 \%$ became active users. The completion rate was $20 \%$ for the fast track and $60 \%$ for those who enrolled in the full track. The relatively high rate of completion of the MOOC can be most likely associated with promotion efforts, namely the precise targeting of potential participants prior to the launch.

The pre-course survey questionnaires were filled out by 681 learners ( $23 \%$ of enrolled participants). The results provided representative information on the age, education, location and professional experience of the participants and, thus, evidence of the heterogeneity of the participants' profiles. The course connected 2905 participants from 98 countries (some individuals who enrolled did not end up taking the course). The distribution of age was as expected, with the largest representation of two age groups: 20-29 and 30-39 years old. The distribution of the current position of employed course participants was also as expected: with the largest share of bottom to middle level managers $(19 \%)$, higher level managers (15\%) and analysts (14\%). Hence, the key target group defined by the developers as young business professionals was met. The age structure is also reflected in the education status of the participants. Of these, $44 \%$ had a full university education and held a Master's degree, while $23 \%$ held a Bachelor's degree. Participants represented various professional contexts (engineering, marketing, sales, HR), with the strongest representation by the IT sector $(36 \%)$, which is not surprising given that IT employees are more accustomed to using online platforms to upgrade their skills. The variation in nationalities, industries and management areas presented an opportunity to tap into very diverse knowledge pools and different manifestations of intrapreneurship, which was the prime intent of the course developers.

Data collected throughout the duration of the course (number of forum posts, forum threads, drop-outs, items visited, points achieved and e-tivities completed) provides evidence on the quantity and quality of knowledge shared among the participants. The course discussion groups resulted in 17 streams and 2239 posts in 294 topics in the forum and Collaboration Space. This volume of exchange requires extended moderation. For example, a common issue was that learners posted similar questions or comments in different threads, which hindered the focus of knowledge exchange. The role of the moderators was to merge or redirect certain discussion streams.

Participant activity measured in the form of online posts was uneven throughout the course. Highest participant input activity took place in the first week (Figure 2), when the participants introduced themselves and shared examples of intrapreneurial projects.

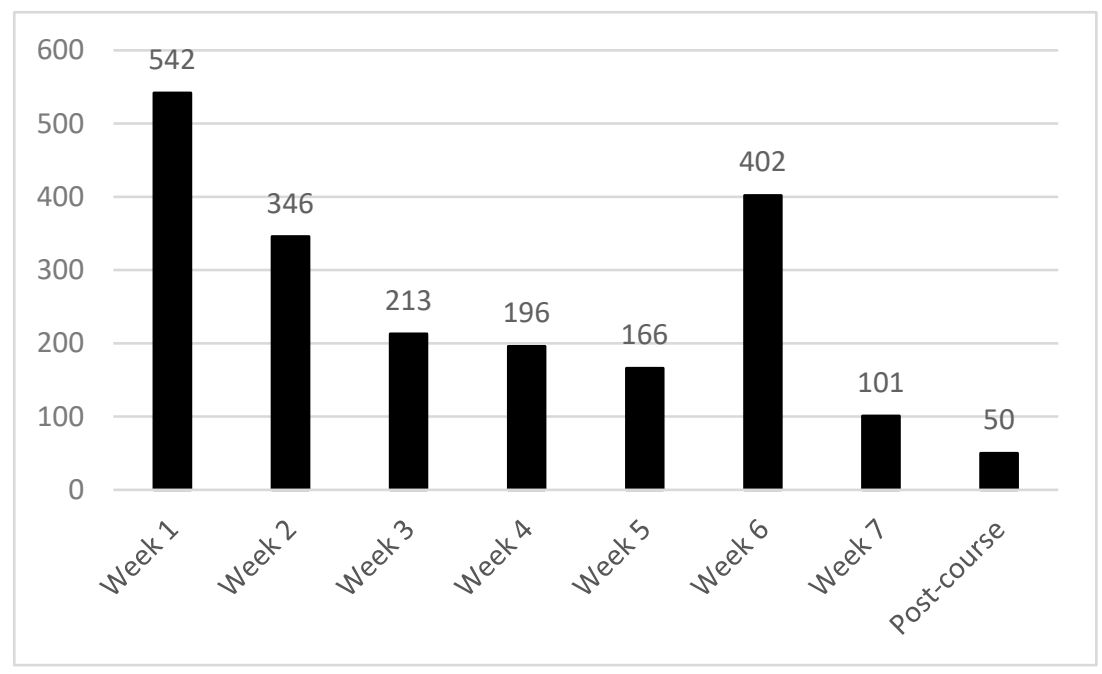

Figure 2. Number of online posts throughout the duration of the MOOC. Source: course statistics. 
Between weeks 2 and 5 the number of posts declined, as some participants left the course. Those who remained, exhibited high levels of engagement and provided input to the course. For example, the e-tivities triggered the creation of 820 intrapreneurial ideas by 594 learners, who identified various opportunities for intrapreneurship in their professional contexts. Forty-eight selected ideas were presented and discussed by the community in knowledge hubs. Finally, in weeks 5 and 6 , the ten best ideas jointly selected by the course community by vote were further developed in teams of eight, pitched and peer-reviewed by the full-track users. Online input peaked again in week 6 (Figure 2), when participants worked in collaboration spaces on their intrapreneurial ideas.

This course resulted in maybe one of the most comprehensive collections of intrapreneurship examples ever collected, with 255 entries and 507 views. During this time, the course discussion groups were extremely active, overflowing with comments, questions, suggestions and stories. The platform functionalities enabled participants to start discussions and forum threads on their own, which resulted in additional discussion streams and cooperation platforms, where people shared intrapreneurship practices, and gave each other advice, suggestions and recommendations. The content analysis of discussion forums feeds identified the most popular discussion streams. These were: Company culture, barriers to intrapreneurship, communication strategies, finding corporate sponsors, presenting ideas in the boardroom and optimal levels of team autonomy. By turning many learners into co-creators of knowledge hubs, the real potential of MOOCs was unleashed, i.e., to create a massive aggregation of experience on a multi-sided digital platform in a time-limited learning ecosystem around a specific topic for the benefit of the entire learning community.

Upon termination of the course, participants filled in the post-course survey. Given that the course had a $20 \%$ completion rate, the 308 filled-in questionnaires ( $11 \%$ of end users) provided representative information on participants' learning experiences. The feedback we received was highly positive. The expectations for the course were fulfilled for the vast majority of respondents $(73 \%$ chose 4 -very good, and 13\% 5-excellent). A number of respondents (27\%) rated the course as excellent in regard to overall benefits, and $47 \%$ as very good. A further $27 \%$ rated knowledge exchange as excellent, and $67 \%$ as very good. The data gathered through the post-course survey portrays the applicability of the knowledge and competences learned in the course in the respective work settings of the learners. Most of the participants evaluated the course in this regard as very good (59\%) or excellent $(14 \%)$. Finally, $83 \%$ of respondents rated the course as excellent and $11 \%$ as very good in terms of recommending it to others.

The data collected through focus groups (representatives of course participants) confirms the results of the post-course survey. All respondents rated the course as beneficial to their target groups. The respondents were surprised by the intensity of exchange between participants: "It was refreshing to observe how people became engaged in this topic and how eager they were to share their experiences and comments with others." The focus groups revealed that it was a unique experience for the participants to have access to so many different areas of knowledge: "I never experienced anything like this before, people had the opportunity to learn so much more than through company training or just self-study. Here, we had the opportunity to discuss in detail all aspects of intrapreneurship. I could join a chat group on the specific aspect that was extremely valuable to me and then join other conversations on other topics." It appears that the exchange orchestrated by the MOOC designers enabled participants to co-create real value added for themselves. The follow-up questions of "why" and "how" revealed the aspects of knowledge exchange that were particularly valuable to the respondents (Table 1). 
Table 1. Most valued aspects of knowledge exchange. Source: focus group interviews.

\begin{tabular}{l} 
Examples of Respondents' Testimonies \\
I learned so much about intrapreneurship in so many \\
organisations. I value most the opportunity to learn about \\
so many examples on intrapreneurship - now I know this \\
can be real. \\
\hline This course strengthened my mindset - anyone can be \\
entrepreneurial. I see the full spectrum of potential that \\
employees hold for the organisation. I gained a new \\
business perspective. I will be keeping an eye out for new \\
ideas of my employees. \\
\hline I see that my company really needs to update its business \\
model. I have so many new ideas now. I have specific ideas \\
that I want to implement in my business. \\
\hline People shared so many useful work-arounds. I learned \\
many new practices from others that I can adopt in my \\
work. Through teamwork, we developed new tools for \\
communicating new ideas and pushing them through. I \\
found the tips on how to build coalitions more helpful. \\
\hline It was a fun learning process. I managed to keep up and \\
enjoyed it. It's a quick way to get up-to-date knowledge \\
from around the world. It was great to learn from people \\
who know so much more than I, and I could learn on my \\
own terms. The flexibility of learning is a huge advantage. \\
It can be addictive, I hope my next MOOC will be just as \\
interesting. \\
\hline It was possible to learn practical little things that you will \\
never read about. I love that people were so open, although \\
they were on the other side of the globe. Everyone was \\
equal in the discussion forums and we addressed each other \\
by our first names. People revealed as much as they wanted \\
about themselves, this was comfortable. \\
Stimulation and reinforcement for further education \\
Exchange of tacit knowledge
\end{tabular}

The data collected confirms that the course became a platform of knowledge exchange and consolidation between multiple different actors across the globe. The focus group discussions revealed that, because of the knowledge exchange dynamics that took place throughout the course, respondents evaluated the course as equal to company training (or even better) due to the possibility of knowledge exchange. Most respondents saw the potential of MOOCs to connect people and consolidate fragmented knowledge on an even larger scale: "MOOCs can be game changers and offer real possibilities for high-quality knowledge exchange between individuals from all over the world." Additionally, "MOOCs can be very effective in connecting people around niche topics, in a way that would be impossible to achieve on a massive scale otherwise."

\section{Discussion}

The aim of this research was to explore the potential role of MOOCs as effective means of employee continuous entrepreneurial education. The results of data analysis support the claim that MOOCs offer a promising method of upgrading entrepreneurial employee skills through knowledge exchange. This study highlighted several aspects of knowledge spillovers that are unique to MOOCs. One aspect is scale. The presented case study exemplifies how a MOOC targeted at a precisely pre-defined audience was able to connect a massive number of individuals around one niche topic, thus far unaddressed in existing online formats. The participants of the MOOC were mostly young employees in early stages of their career from all over the world, exercising or willing to exercise intrapreneurship at their workplaces. The participants' engagement, abundant exchange and feedback suggest that they would not have been able to connect otherwise and were, therefore, "hungry" for exchange. Additionally, the controlled anonymity of online interactions may influence a higher level of openness than if the same participants were to meet face-to-face. 
The second emerging aspect of knowledge spillover effects in this case study was time. The learning in real-time aspect of a MOOC may be the pulling factor for many participants; if the employment of a multi-sided digital platform was limited to joint content creation, spread over longer periods of time, the results may have been different. This case study exemplifies that time restrictions can have a positive impact on the density of interactions, as actors are aware that they need to engage here and now for a pre-defined limited amount of time. The design of a MOOC, specifically the distribution of e-tivities throughout the course, determines the peak interactions where actors rapidly generate new content. The aspect of time is also reflected in the generation and consolidation of knowledge on a just-in-time basis. MOOC participants provided their input based on the knowledge and experience they held at the time of the course. Therefore, they shared their most up-to-date knowledge (including examples, current developments in the field, newest tools and methods). No other means provides such current knowledge in such massive amounts in the area of intrapreneurship.

This study offers important conceptual and practical contributions to two streams of academic research. First, it extends the knowledge spillover theory of entrepreneurship beyond its current boundaries to include MOOCs as a potential platform for effective knowledge spillovers. This study addresses one of the leading research questions put forward by the knowledge spillover theory of entrepreneurship: "Where do these knowledge spillovers come from?" [45]. This paper provides insights into MOOCS, an area where knowledge spillover takes place on a massive scale and which has, thus far, been sidelined by scholarship. It confirms the claim that knowledge spillovers can be the source of entrepreneurial opportunities; online activities within the MOOC triggered the identification of numerous opportunities and the creation of 820 intrapreneurial ideas by 594 learners. It also challenges the assumption of the knowledge spillover theory of entrepreneurship in regard to geographical proximity, as the overwhelming majority of empirical studies confirms the importance of close proximity to the source of knowledge [45]. Conversely, this study exemplifies that knowledge spillover, lifted out of its geographical limitations, can take place on a multi-sided digital platform in ways which create tangible value for participants. Furthermore, the tacit knowledge "transport" mechanism has been traditionally regarded in the past as limited to informal conversation $[29,46]$. The findings of this study suggest that online exchange between MOOC participants can trigger cross-side exchange in the area of informal and tacit knowledge sharing. This is most likely conditioned by the anonymity of participants involved in the exchange.

Second, the findings provide insights for entrepreneurial education in the digital age and add to our understanding of employee continuous learning. Using a real-life example, the case study exemplifies three important digital advantages, which help to conceptualise the digital entrepreneurial learning environment [11] and activate network learning [47]: (i) digitalisation decouples form and function, reducing the importance of assets and physical infrastructure, (ii) it promotes disintermediation enabling direct connections between various actors, and finally, (iii) it drives generativity, enabling dispersed audiences to create and take advantage of digital platforms. The presented case exemplifies all these advantages and presents how a carefully designed and moderated MOOC can be an effective way to enable the bottom-up, user-driven rise and formation of digital communities $[24,48]$ within new knowledge clusters. The showcased example has exposed the MOOC participants to new pools of knowledge. This is an important aspect, given that, usually, individuals and firms have limited, often specialised knowledge bases and they encounter numerous challenges accessing external sources of knowledge [47]. The MOOC became a means by which knowledge was exchanged on an inter-company level and it established a system of linkages with free flow of knowledge between a range of participants, creating not only useful knowledge, but also a common aim, in this case, intrapreneurship within organisations [34]. With their approach in terms of connecting critical masses of learners from different backgrounds around a specific topic, MOOCs are able to create platforms of seamless knowledge exchange via intensive cross-side network effects and knowledge spillovers [49].

Third, the study has significant practical implications. It supports the claim that entrepreneurial education infrastructure needs to adapt to the new emerging forms of connecting various actors in 
order to integrate and disseminate knowledge effectively. This study offers important insights and practical implications for institutions willing to engage in MOOCs on that quest. It confirms that, in addition to the traditional teaching and knowledge transfer roles, MOOCs can play the role of trusted intermediaries and we exemplify one way of how this can be achieved via multi-sided digital platforms. The findings of this study suggest that MOOCs can be effective intermediaries, connecting distant actors on a massive scale, but only when several important conditions are met: (i) the course must be targeted to a specific carefully selected audience, (ii) its content must be up-to-date and highly relevant for the target audience, (iii) participants should be able to create new and develop existing content, (iv) the MOOC must create plenty of opportunities for participants to interact, discuss issues, and share knowledge and experience in a moderated, user-friendly setting, and, finally, (v) participants should have the liberty to launch new discussion streams in separate knowledge hubs. The case study shows that multi-sided platforms are not merely matchmakers that bring together different parties [12], and that the platform leaders must take on a proactive role in orchestrating network dynamics and sustaining the cross-side network effects. This study also demonstrates how specific tools, such as moderated discussion forums or e-tivities within a MOOC, can raise the density of interactions between digital community members, strengthening this critical aspect of networks [50] and enabling actors to capture substantial value for themselves.

Given all the above contributions, it must be acknowledged that MOOCs entail a significant and inherent limitation. While knowledge exchange and diffusion are free from specific limitations, these processes are temporary and subject to time restrictions, as MOOC participants remain connected only for a fixed period of time. As signalled above, however, time restrictions can have a mobilising effect on the ecosystem actors. Additionally, the authors have indicated that even though the digital communities created by MOOCs are temporary, the knowledge dissemination effects can be long-term [51]. The majority of our MOOC participants declared that they found their newly acquired competences very useful at work. The long-term effect of the course was further confirmed by focus group interviews, where respondents stated that they would be willing to apply their new knowledge at work.

\section{Conclusions, Limitations and Future Research}

The results of this study suggest that MOOCs carry the potential to serve as effective means for employee continuous entrepreneurial learning. The case study used, demonstrates that high-quality MOOCs can enable the creation of temporary digital communities around various knowledge pools. They can stimulate knowledge exchange, and new knowledge creation and consolidation, given that they are targeted towards a specific pre-defined audience and that they employ digital tools which ensure a high density of interactions between participants. The case study also shows that a narrowly predetermined set of digital learning actors, with common experiences and aspirations can result in massive exchange, which in turn can lead to knowledge spillovers.

The study has some limitations. The number of interviews conducted and the quantitative data collected is not large enough to allow for generalisations, and inferences are limited to the presented case. Moreover, the usefulness of the course was tested only at one period in time, directly after finalising the course by the participants. A more reliable verification would require the study of the long-term effects of the course on participants' professional experiences.

These limitations provide an avenue for future research, which should test further the long-term effects of MOOC contributions to entrepreneurial learning. Given the high dispersion of network members, can the digital entrepreneurial learning environment become mainstream in entrepreneurship continuous education or does it only serve a complementary role to traditional learning formats? Future studies can compare the scope and effects of contributions stemming from online knowledge exchange within temporary knowledge clusters to traditional forms of entrepreneurial learning formats.

Funding: This publication was co-financed by the European Education, Audiovisual and Culture Executive Agency as part of Erasmus+ project "Corporate EDUpreneurship-Benefitting Start-ups, Universities and Corporates across Europe", PROJECT NUMBER: 600899-EPP-1-2018-1-AT-EPPKA2-KA. 
Conflicts of Interest: The author declares no conflict of interest.

\section{References}

1. Lewrick, M.; Omar, M.; Raeside, R.; Sailer, K. Education for entrepreneurship and innovation: Management capabilities for sustainable growth and success. World J. Entrep. Manag. Sustain. Dev. 2011, 6, 1-18. [CrossRef]

2. Yin, R.K. Case Study Research and Applications: Design and Methods; Sage Publications: New York, NY, USA, 2017.

3. Pasieczny, J.; Glinka, B. Organizational dysfunctions: Sources and areas. Entrep. Bus. Econ. Rev. 2016, 4, 213-223. [CrossRef]

4. Postuła, A.; Majczyk, J. Managers and Leaders in Need of Entrepreneurial Competences. Entrep. Bus. Econ. Rev. 2018, 6, 91-103. [CrossRef]

5. Sady, M.; Żak, A.; Rzepka, K. The Role of Universities in Sustainability-Oriented Competencies Development: Insights from an Empirical Study on Polish Universities. Adm. Sci. 2019, 9, 62. [CrossRef]

6. Santandreu-Mascarell, C.; Garzon, D.; Knorr, H. Entrepreneurial and innovative competences, are they the same? Manag. Decis. 2013, 51, 1084-1095. [CrossRef]

7. Kakouris, A. Entrepreneurship pedagogies in lifelong learning: Emergence of criticality? Learn. Cult. Soc. Interact. 2015, 6, 87-97. [CrossRef]

8. Nabi, G.; Liñán, F.; Fayolle, A.; Krueger, N.; Walmsley, A. The impact of entrepreneurship education in higher education: A systematic review and research agenda. Acad. Manag. Learn. Educ. 2017, 16, 277-299. [CrossRef]

9. Kimiloglu, H.; Ozturan, M.; Kutlu, B. Perceptions about and attitude toward the usage of e-learning in corporate training. Comput. Hum. Behav. 2017, 72, 339-349. [CrossRef]

10. Acs, Z.J.; Audretsch, D.B.; Lehmann, E.E. The knowledge spillover theory of entrepreneurship. Small Bus. Econ. 2013, 41, 757-774. [CrossRef]

11. Autio, E.; Nambisan, S.; Thomas, L.D.; Wright, M. Digital affordances, spatial affordances, and the genesis of entrepreneurial ecosystems. Strateg. Entrep. J. 2018, 12, 72-95. [CrossRef]

12. Helfat, E.C.; Raubitschek, R.S. Dynamic and integrative capabilities for profiting from innovation in digitalplatform-based ecosystems. Res. Policy 2018, 47, 1391-1399. [CrossRef]

13. Teece, D.J. Dynamic capabilities and (digital) platform lifecycles. Entrepreneurship, Innovation, and Platforms 2017, 37, 211-225.

14. European Parliament and Council. Recommendation of the European Parliament and of the Council of 18 December 2006 on Key Competences for Lifelong Learning; European Commission: Brussels, Belgium, 2006; pp. 10-18.

15. Rae, D. Entrepreneurial learning: A narrative-based conceptual model. J. Small Bus. Enterp. Dev. 2005, 12, 323-335. [CrossRef]

16. Delgado-Algarra, E.J.; Román-Sánchez, I.M.; Ordonez Olmedo, E.; Lorca-Marín, A.A. International MOOC Trends in Citizenship, Participation and Sustainability: Analysis of Technical, Didactic and Content Dimensions. Sustainability 2019, 11. [CrossRef]

17. Gibb, A.A. In pursuit of a new enterprise and entrepreneurship paradigm for learning: Creative destruction, new values, new ways of doing things and new combinations of knowledge. Int. J. Manag. Rev. 2002, 4, 213-232. [CrossRef]

18. Pittaway, L.; Cope, J. Simulating entrepreneurial learning: Integrating experiential and collaborative approaches to learning. Manag. Learn. 2007, 38, 211-233. [CrossRef]

19. Dodson, M.N.; Kitburi, K.; Berge, Z.L. Possibilities for MOOCs in corporate training and development. Perform. Improv. 2015, 54, 14-21. [CrossRef]

20. Pisoni, G. Strategies for pan-european implementation of blended learning for innovation and entrepreneurship (i\&e) education. Educ. Sci. 2019, 9, 124. [CrossRef]

21. Morcillo, P.; Rodriguez-Anton, J.M.; Rubio, L. Corporate culture and innovation: In search of the perfect relationship. Int. J. Innov. Learn. 2007, 4, 547-570. [CrossRef]

22. Ellis, P.F.; Kuznia, K.D. Corporate eLearning impact on employees. Glob. J. Bus. Res. 2014, 8, 1-15.

23. Chen, E.T. Successful E-Learning in corporations. Commun. IIMA 2008, 8, 45-54.

24. Strother, J.B. An assessment of the effectiveness of e-learning in corporate training programs. Int. Rev. Res. Open Distrib. Learn. 2002, 3, 1-17. [CrossRef] 
25. Adler, P.S.; Kwon, S.W. Social capital: Prospects for a New Concept. Acad. Manag. Rev. 2002, $27,17-40$. [CrossRef]

26. Clarysse, B.; Wright, M.; Bruneel, J.; Mahajan, A. Creating value in ecosystems: Crossing the chasm between knowledge and business ecosystems. Res. Policy 2014, 43, 1164-1176. [CrossRef]

27. Jack, S.L. The Role, Use and Activation of Strong and Weak Network Ties: A Qualitative Analysis. J. Manag. Stud. 2005, 42, 1233-1259. [CrossRef]

28. Uzzi, B. Social Structure and Competition in Interfirm Networks: The Paradox of Embeddedness. Adm. Sci. Q. 1997, 42, 35-67. [CrossRef]

29. Jaffe, A.B. Technological opportunity and spillovers of R\&D: Evidence from firms' patents profits, and market value. Am. Econ. Rev. 1986, 76, 984-1001.

30. Li, W.; Badr, Y.; Biennier, F. Digital ecosystems: Challenges and prospects. In Proceedings of the International Conference on Management of Emergent Digital EcoSystems, ACM, Addis Ababa, Ethiopia, 28-31 October 2012; pp. 117-122.

31. Jansen, D.; Schuwer, R. Institutional MOOC Strategies in Europe Status Report Based on a mApping Survey Conducted in October-December 2014; EADTU: Maastricht, The Netherlands, 2018; Available online: https: //www.surfspace.nl/media/bijlagen/artikel-1763-22974efd1d43f52aa98e0ba04f14c9f3.pdf (accessed on 18 October 2019).

32. Meinel, C.; Schweiger, S.A. Virtual Social Learner Community-Constitutive Element of MOOCs. Educ. Sci. 2016, 6. [CrossRef]

33. Siemens, G. Connectivism: A learning theory for the digital age. Int. J. Ind. Technol. Distance Learn. 2005, 2, 3-10.

34. Najafi, H.; Rolheiser, C.; Håklev, S.; Harrison, L. Variations in Pedagogical Design of Massive Open Online Courses (MOOCs) Across Disciplines. Teach. Learn. Inq. 2017, 5, 47-64. [CrossRef]

35. Karlsson, N.; Godhe, A.L. Creating a Community Rather Than a Course-Possibilities and Dilemmas in an MOOC. Educ. Sci. 2016, 6. [CrossRef]

36. Conole, G.G. MOOCs as disruptive technologies: Strategies for enhancing the learner experience and quality of MOOCs. Rev. Educ. Distancia 2013, 39. Available online: https://revistas.um.es/red/article/view/234221 (accessed on 12 November 2019). [CrossRef]

37. Fournier, H.; Kop, R.; Durand, G. Challenges to research in MOOCs. MERLOT J. Online Learn. Teach. 2014, 10, 1-15.

38. Kizilcec, R.F.; Saltarelli, A.J.; Reich, J.; Cohen, G.L. Closing global achievement gaps in MOOCs. Science 2017, 355, 251-252. [CrossRef]

39. Zawacki-Richter, O.; Bozkurt, A.; Alturki, U.; Aldraiweesh, A. What research says about MOOCs-An explorative content analysis. Int. Rev. Res. Open Distrib. Learn. 2018, 19, 242-259. [CrossRef]

40. Antoncic, J.; Antoncic, B. Employee satisfaction, intrapreneurship and firm growth: A model. Ind. Manag. Data Syst. 2011, 111, 589-607. [CrossRef]

41. Creswell, J.W. Qualitative Inquiry and Research Design: Choosing Among Five Traditions; Sage: Thousand Oaks, CA, USA, 1998.

42. Lee, A.S. Case studies as natural experiments. Hum. Relat. 1989, 42, 117-137. [CrossRef]

43. Onah, D.F.; Sinclair, J.; Boyatt, R. Dropout rates of massive open online courses: Behavioural patterns. EDULEARN14 Proc. 2014, 1, 5825-5834.

44. Salmon, G. E-Tivities, the Key to Active Online Learning, 2nd ed.; Routlegde: London, UK; New York, NY, USA, 2013.

45. Ghio, N.; Guerini, M.; Lehmann, E.E.; Rossi-Lamastra, C. The emergence of the knowledge spillover theory of entrepreneurship. Small Bus. Econ. 2015, 44,1-18. [CrossRef]

46. Sternberg, R. Entrepreneurship, Proximity and Regional Innovation Systems. Tijdschr. Voor Econ. En Soc. Geogr. 2007, 98, 652-666. [CrossRef]

47. Caseiro, N.; Coelho, A. The influence of Business Intelligence capacity, network learning and innovativeness on startups performance. J. Innov. Knowl. 2019, 4, 139-145. [CrossRef]

48. Dini, P.; Iqani, M.; Mansell, R. The (im)possibility of interdisciplinary lessons from constructing a theoretical framework for digital ecosystems. Cult. Theory Crit. 2011, 52, 3-27. [CrossRef] 
49. Yang, L.X.; Yang, X.; Zhijun, Z. MOOC: A New Mode of Integrating and Sharing Knowledge Resources in Colleges and Universities. In Proceedings of the 2016 8th International Conference on Information Technology in Medicine and Education (ITME), Fuzhou, China, 23-25 December 2016.

50. Feld, B. Startup Communities: Building an Entrepreneurial Ecosystem in Your City; Wiley: New York, NY, USA, 2012.

51. Kim, P.; Chung, C. Creating a temporary spontaneous mini-ecosystem through a MOOC. In MOOCs and Open Education Around the World; Bonk, C.J., Lee, M.M., Reeves, T.C., Reynolds, T.H., Eds.; Routlegde: New York, NY, USA, 2015; pp. 157-168.

(C) 2020 by the author. Licensee MDPI, Basel, Switzerland. This article is an open access article distributed under the terms and conditions of the Creative Commons Attribution (CC BY) license (http://creativecommons.org/licenses/by/4.0/). 